\title{
Lipoprotein(a) and cardiovascular disease: prediction, attributable risk fraction, and estimating benefits from novel interventions
}

\author{
Paul Welsh $\mathbb{1}^{1}{ }^{1 \dagger}$, Claire Welsh $\mathbb{1}^{2}{ }^{2 \dagger}$, Carlos A. Celis-Morales $\mathbb{1}^{1}{ }^{1,3}$, \\ Rosemary Brown $\mathbb{D}^{1}{ }^{1}$, Frederick K. Ho $\mathbb{1}^{3}$, Lyn D. Ferguson $\left.{ }^{1}\right)^{1}$, \\ Patrick B. Mark (1) ${ }^{1}$, James Lewsey $\mathbb{1}^{3}{ }^{3}$, Stuart R. Gray $\mathbb{1}^{1}{ }^{1}$, Donald M. Lyall $\mathbb{1}^{3}{ }^{3}$, \\ Jason M.R. Gill (1) ${ }^{1}$, Jill P. Pell $\mathbb{1}^{3}{ }^{3}$, James A. de Lemos $\mathbb{C}^{4}{ }^{4}$, Peter Willeit $\mathbb{( D}^{5,6}$, and \\ Naveed Sattar $\mathbb{1}^{1} *$
}

\begin{abstract}
${ }^{1}$ Institute of Cardiovascular and Medical Sciences, University of Glasgow, BHF Glasgow Cardiovascular Research Centre, 126 University Place, Glasgow G12 8TA, UK; ${ }^{2}$ Population Health Sciences Institute, Faculty of Medical Sciences, Newcastle University, Newcastle, UK; ${ }^{3}$ Institute of Health and Wellbeing, University of Glasgow, 1 Lilybank Gardens, Glasgow G12 8RZ, UK; ${ }^{4}$ Division of Cardiology, Department of Medicine, University of Texas Southwestern Medical Center, 5323 Harry Hines Blvd, Dallas, TX 75390 , USA; ${ }^{5}$ Department of Neurology, Medical University of Innsbruck, Anichstraße 35, Innsbruck 6020, Austria; and ${ }^{6}$ Department of Public Health and Primary Care, University of Cambridge, Strangeways Research Laboratory, Worts Causeway, Cambridge CB1 8RN, UK
\end{abstract}

Received 7 August 2020; revised 13 August 2020; editorial decision 25 August 2020; accepted 26 August 2020

\begin{abstract}
Aims
To investigate the population attributable fraction due to elevated lipoprotein (a) $(L p(a))$ and the utility of measuring $L p(a)$ in cardiovascular disease (CVD) risk prediction.

Methods

and results

In 413734 participants from UK Biobank, associations of serum Lp(a) with composite fatal/non-fatal CVD ( $n=10066$ events), fatal CVD ( $n=3247)$, coronary heart disease (CHD; $n=18292)$, peripheral vascular disease (PVD; $n=2716)$, and aortic stenosis $(n=901)$ were compared using Cox models. Median Lp(a) was $19.7 \mathrm{nmol} / \mathrm{L}$ (interquartile interval 7.6$75.3 \mathrm{nmol} / \mathrm{L}$ ). About $20.8 \%$ had $\mathrm{Lp}(\mathrm{a})$ values $>100 \mathrm{nmol} / \mathrm{L} ; 9.2 \%$ had values $>175 \mathrm{nmol} / \mathrm{L}$. After adjustment for classical risk factors, $1 \mathrm{SD}$ increment in log Lp(a) was associated with a hazard ratio for fatal/non-fatal CVD of 1.12 [95\% confidence interval (Cl) 1.10-1.15]. Similar associations were observed with fatal CVD, CHD, PVD, and aortic stenosis. Adding Lp(a) to a prediction model containing traditional CVD risk factors in a primary prevention group improved the C-index by +0.0017 (95\% Cl 0.0008-0.0026). In the whole cohort, Lp(a) above $100 \mathrm{nmol} / \mathrm{L}$ was associated with a population attributable fraction (PAF) of 5.8\% (95\% Cl 4.9-6.7\%), and for $L p(a)$ above $175 \mathrm{nmol} / \mathrm{L}$ the PAF was 3.0\% (2.4-3.6\%). Assuming causality and an achieved $L p(a)$ reduction of $80 \%$, an ongoing trial to lower $L p(a)$ in patients with CVD and $L p(a)$ above $175 \mathrm{nmol} / \mathrm{L}$ may reduce CVD risk by $20.0 \%$ and CHD by $24.4 \%$. Similar benefits were also modelled in the whole cohort, regardless of baseline CVD.
\end{abstract}

Conclusion Population screening for elevated $L p(a)$ may help to predict CVD and target $L p(a)$ lowering drugs, if such drugs prove efficacious, to those with markedly elevated levels.

Keywords Lipoprotein(a) • Cardiovascular disease • Epidemiology • Risk prediction

\footnotetext{
* Corresponding author. Tel: +44 141330 3419, Email: naveed.sattar@glasgow.ac.uk

† The first two authors contributed equally to the study.

(C) The Author(s) 2020. Published by Oxford University Press on behalf of the European Society of Cardiology.

This is an Open Access article distributed under the terms of the Creative Commons Attribution License (http://creativecommons.org/licenses/by/4.0/), which permits unrestricted reuse, distribution, and reproduction in any medium, provided the original work is properly cited.
} 


\section{Introduction}

Lipoprotein (a) $(L p(a))$ is a low-density lipoprotein (LDL) particle made by the liver, comprised of both an apolipoprotein(a) and an apolipoprotein B protein. Its structure is highly heterogeneous, but levels of $L p(a)$ are $80-90 \%$ genetically determined and relatively stable across the life course.

Epidemiological evidence shows strong associations of circulating $\mathrm{Lp}$ (a) with atherogenesis and consequent risk of cardiovascular disease (CVD). For instance, in a recent meta-analysis of statin trial data, those with $L p(a)$ concentrations above $50 \mathrm{mg} / \mathrm{dL}$ were at $35 \%$ higher risk of incident CVD events [95\% confidence interval (Cl) 11-66\%] compared to those with $\mathrm{Lp}(\mathrm{a})<15 \mathrm{mg} / \mathrm{dL}(\sim 30 \mathrm{nmol} / \mathrm{L})$ after adjusting for confounders. ${ }^{1}$ Similar data have been reported in population studies. ${ }^{2,3}$ Furthermore, genetic data and basic science support the notion that the association is causal. ${ }^{4,5}$ This has led to interest both in the potential for $L p(a)$ to serve as a biomarker to enhance CVD risk prediction, ${ }^{6}$ and as a therapeutic target. Indeed, $L p(a)$ lowering drugs may be a viable therapeutic option, with at least one drug moving to Phase 3 in the Lp(a)HORIZON trial. ${ }^{7}$ Further, proprotein convertase subtilisin/ kexin type 9 (PCSK9) inhibitors, which lower LP(a) concentrations by around $27 \%$, may be particularly beneficial in reducing risk in patients with previous CVD and substantially raised $L p(a))^{8,9}$

Currently, most guidelines and consensus statements do not advocate widespread screening for elevated $L p(a)$ and suggest focused measurement considering high $L p(a)$ as a risk enhancer. ${ }^{10-12}$ However, the recently released ESC/EAS guidelines suggested a 'one-off measurement of $L p(a)$ may help to identify people with very high inherited $\mathrm{Lp}$ (a) levels who may have a substantial lifetime risk of atherosclerotic cardiovascular disease (ASCVD), ${ }^{13}$ Although $L p(a)$ is sometimes measured in patients with suspected familial hypercholesterolaemia, ${ }^{14}$ it is currently not routinely measured in general practice. ${ }^{11}$ In addition, there is conflicting advice on what constitutes a 'high' $L p(a)$ level. Several guidelines and consensus statements advocate the $50 \mathrm{mg} / \mathrm{dL}$ ( $\sim 125 \mathrm{nmol} / \mathrm{L}$ ) cut-off ${ }^{10,11,15}$ as this corresponds to the 80th percentile in one cohort study, ${ }^{16}$ but the 2016 Canadian Cardiovascular Society Guidelines use $30 \mathrm{mg} / \mathrm{dL}$ on the basis of elevated CVD risk ( $\sim 75 \mathrm{nmol} /$ L). ${ }^{17}$ The Lp(a)HORIZON trial uses $70 \mathrm{mg} / \mathrm{dL}(\sim 175 \mathrm{nmol} / \mathrm{L})$ as an inclusion criterion. ${ }^{7}$ The lack of data from a single large cohort with consistent phenotyping is a significant limitation in interpreting the existing literature, impacting our understanding of the prevalence of high $\operatorname{Lp}(a)$, and its consequences for CVD risk.

UK Biobank is a large prospective population-based cohort study carried out in the UK, with information on baseline biochemistry measurements including routine lipids and $L p(a)$ measured in a central laboratory. We aimed to use this resource to explore the shape of the association of $L p(a)$ with a range of distinct CVD outcomes to investigate the population attributable risk fraction for CVD that might be explained by elevated $L p(a)$, and to predict what might be the effect of novel $L p(a)$-lowering therapies based on these data and recent relevant trials.

\section{Methods}

UK Biobank was conducted across 22 assessment centres across the UK between March 2006 and December 2010 and recruited 502624 participants aged 37-73. A repeat visit was conducted between 2009 and 2013 for 20345 individuals. Baseline biological measurements were recorded and touch-screen questionnaires were administered according to a standardized protocol. ${ }^{18,19}$ UK Biobank received ethical approval from the North West Multi-Centre Research Ethics Committee (REC reference: 11/NW/03820). All participants gave written informed consent before enrolment in the study, which was conducted in accordance with the principles of the Declaration of Helsinki.

For the present analysis, ethnicity was coded as White, South Asian, Black, or mixed/other. Smoking status was categorized into never or former/current smoking. Systolic and diastolic blood pressure were measured at the baseline visit, preferentially using an automated measurement, but using manual measurement where this was not available. Blood collection sampling procedures for the study have been previously described and validated. ${ }^{20}$ The definition of baseline diabetes included self-reported type 1 or type 2 diabetes, those with a primary or secondary hospital diagnoses relating to diabetes at baseline (ICD-10 codes E10-E14.9), and those who reported using diabetes medications. Statin (categorized to include other cholesterol lowering medications) and blood pressure medication use were also recorded from self-report. Baseline CVD was defined as self-reported myocardial infarction, stroke, or transient ischaemic attack.

Biochemistry measures were performed at a dedicated central laboratory on around 480000 baseline samples between 2014 and 2017. During the project, the UK Biobank laboratories were successfully externally audited against the ISO 17025:2005 standard. Assays included serum total cholesterol and high-density lipoprotein (HDL) cholesterol (Beckman Coulter, UK on an AU5800 platform) and Lp(a) (Randox Bioscience, UK on an AU5800 platform) and all were run using internal controls and an external quality assurance scheme. Data were adjusted by UK Biobank centrally before release to adjust for pre-analytical variables. For $L p(a)$, low-, medium-, and high-quality control materials ran with coefficients of variation of $\leq 6.1 \%$. Further details of these measurements can be found in the UK Biobank online showcase and protocol (http:// www.ukbiobank.ac.uk, accessed 9 September 2020). The Randox Lp(a) assay is calibrated in $\mathrm{nmol} / \mathrm{L}$, reflecting the concentration of particles rather than the mass of particles and is traceable to the WHO/IFCC reference material. The minimum reported concentration of $L p(a)$ was $3.8 \mathrm{nmol} / \mathrm{L}$ and the maximum was $189 \mathrm{nmol} / \mathrm{L}$; participants who had levels below the lower level $(n=48360)$ were coded as having an Lp $(a)$ concentration of $2.88 \mathrm{nmol} / \mathrm{L}$, and above the upper level $(n=34195)$ coded as $250 \mathrm{nmol} / \mathrm{L}$ for continuous analyses.

Date and cause of death were obtained from death certificates held by the National Health Service (NHS) Information Centre for participants from England and Wales and the NHS Central Register Scotland for participants from Scotland. Only primary causes of death listed on the death certificate were included in this analysis. Non-fatal outcomes were ascertained by linkage of participant study data to Hospital Episode Statistics from the National Health Service. The primary outcome of interest was ASCVD; this and secondary outcomes are defined in Supplementary material online.

End of follow-up for each participant was recorded as the date of death or the date of end of follow-up for the assessment centre attended, whichever came first. The period at risk of each participant began on the date of their assessment.

\section{Statistical analyses}

The association of continuous log-transformed Lp(a) with other lipid variables was tested using Pearson correlation coefficients. LP(a) was analysed using a number of different models, reflecting existing uncertainty regarding cut-offs for 'abnormal' levels. LP(a) was categorized into 
multiple distinct categorical variables, with upper cut-offs at $20 \mathrm{nmol} / \mathrm{L}$ and $100 \mathrm{nmol} / \mathrm{L}$ or $125 \mathrm{nmol} / \mathrm{L}$ or $150 \mathrm{nmol} / \mathrm{L}$ or $175 \mathrm{nmol} / \mathrm{L}$. Sex and ethnicity-specific centiles (50th, 75th, 80th, 90th, and 95th centiles) for Lp(a) were also developed, using binomial exact Cls to yield 95\% Cls for the centiles. The sex and ethnicity-specific 80th centile were chosen to create a binary 'high' category for $L p(a)$. Log-transformed $L p(a)$ was also analysed as a continuous variable. Classical risk factors were expressed as mean (standard deviation) if symmetrically distributed, median (interquartile range) if skewed, and number (\%) if categorical. The distribution of classical risk factors by categories of outcome or exposure of interest was assessed using unpaired two-tail $t$-tests, a Wilcoxon rank-sum, or a $\chi^{2}$ test, respectively.

Prospectively, the cohort was analysed as a whole cohort and was also stratified as a primary prevention cohort (participants without baseline CVD and not taking a statin) and as a high-risk cohort (participants with baseline CVD and/or taking a statin). We assessed agreement between baseline and repeated $L p(a)$ measurements in those with available data using Lin's Correlation coefficient and the mean difference in measurement, along with $95 \%$ limits of agreement, and using the coefficient of variation across the two visits.

Rates of the primary composite CVD outcome were investigated in unadjusted models, splitting the cohort by the specified $L p(a)$ categories. Associations of continuous and categorical $L p(a)$ with outcomes of interest were investigated using Cox-proportional hazard models in the whole cohort adjusting for classical risk factors. The ability of $L p(a)$ to improve prediction of CVD was tested by assessing improvement over a base model containing all elements from the Pooled Cohort Equation (Supplementary material online).

Population attributable fractions in the exposed, with $95 \% \mathrm{Cls}$, were estimated using two adjusted Cox models and the punafcc post-estimate command in STATA. The model added LP(a) at a number of binary cut-offs and was designed to estimate the causal effect of 'elevated' $L p(a)$ in the whole cohort for each outcome. The second model, intended to represent anticipated benefit of therapeutic intervention in those with elevated $L p(a)$, added $L p(a)$ as a four-category variable with concentration $>175 \mathrm{nmol} / \mathrm{L}$ (representing the Lp(a)HORIZON trial recruitment criterion $\left.{ }^{7}\right), 40-175 \mathrm{nmol} / \mathrm{L}, \quad 30$ $40 \mathrm{nmol} / \mathrm{L}$ (the estimated attained $\mathrm{Lp}(\mathrm{a})$ assuming an $80 \%$ reduction on-treatment ${ }^{21}$ ), and $<30 \mathrm{nmol} / \mathrm{L}$. This model was then used to test the estimated proportional reduction in CVD events among those with $L p(a)>175 \mathrm{nmol} / \mathrm{L}$ when concentration was lowered to the 30 $40 \mathrm{nmol} / \mathrm{L}$ range. The model was run specifically in those with baseline CVD and in the whole cohort.

All analyses were performed using STATA 15.1 (StataCorp LP) and R (version 3.5.1).

\section{Results}

\section{Cross-sectional associations}

Of 502624 people included in the study, complete data on covariates, including $L p(a)$ were available in 413734 participants. Median $\mathrm{Lp}(\mathrm{a})$ in the cohort was $19.7 \mathrm{nmol} / \mathrm{L}$ (interquartile interval $7.6-$ $75.3 \mathrm{nmol} / \mathrm{L})$. In participants without baseline CVD and not taking a statin $(n=340339)$ median Lp(a) was $19.1 \mathrm{nmol} / \mathrm{L}$ (interquartile interval $7.6-70.5 \mathrm{nmol} / \mathrm{L})$. The 80th centile in the whole cohort was $104.5 \mathrm{nmol} / \mathrm{L}$ (95\% Cl 103.8-105.3). In the whole cohort, 85932 (20.8\%) had Lp(a) above $100 \mathrm{nmol} / \mathrm{L}, 68603$ (16.6\%) above $125 \mathrm{nmol} / \mathrm{L}, 52159$ (12.6\%) above $150 \mathrm{nmol} / \mathrm{L}$, and 38111 (9.2\%) above $175 \mathrm{nmol} / \mathrm{L}$. Sex and ethnicity-specific cut-offs show that women and participants with black ethnicity had higher $L p(a)$ concentrations (Figure 1).

Lipoprotein (a) had weak positive associations with total cholesterol $(r=0.11)$, HDL cholesterol $(r=0.04)$, and LDL cholesterol $(r=0.12)$ ( $P$ for all $<0.0001)$. These associations were only nominally stronger in the population who did not report taking statins $(r=0.14$, $0.05,0.16$, respectively). Participants with elevated $L p(a)$ were generally slightly older, had slightly higher systolic blood pressure and total cholesterol and were more likely to have baseline CVD (Table 1).

\section{Repeated measures of lipoprotein (a)}

Fourteen thousand, two hundred, and forty-eight participants from the baseline cohort had repeated measures of $L p(a)$ available. At the follow-up visit, $L p(a)$ was $2.9 \mathrm{nmol} / \mathrm{L}$ higher, the $95 \%$ limits of agreement for $L p(a)$ between the two visits were $-37.5,43.3 \mathrm{nmol} / \mathrm{L}$, and the median coefficient of variation was $12.6 \%$ (interquartile range 3.8-24.7\%). The concordance coefficient was 0.958 (95\% Cl 0.9570.959) (Supplementary material online, Figure S1).

\section{Univariable association of lipoprotein (a) with outcomes}

Median follow-up time for the composite CVD outcome was 8.9 years (interquartile range 8.2-9.5) in the whole cohort. The composite CVD outcome occurred in 10066 participants (2.4\%), and fatal CVD occurred in 3247 participants $(0.8 \%)$ in the whole cohort. The composite CVD outcome occurred in 6125 participants (1.8\%), and fatal CVD occurred in 1627 participants (0.5\%) in the subgroup without baseline CVD and not taking a statin.

Baseline Lp(a) was higher among the participants who went on to experience the composite CVD outcome and the fatal CVD outcome (Supplementary material online, Table S1). Lp(a) was also higher among those who went on to experience coronary heart disease (CHD), peripheral vascular disease (PVD), or aortic valve stenosis but was not higher among those who went on to experience ischaemic stroke, heart failure (Supplementary material online, Table S1).

\section{Multivariable association of lipoprotein (a) with outcomes}

In the whole cohort, there was an independent association of $1 \mathrm{SD}$ increase in log Lp(a) with the primary composite CVD outcome [hazard ratio (HR) $1.12(95 \% \mathrm{Cl} 1.10-1.15)]$ after adjusting for classical risk factors statin use and baseline CVD. In the whole cohort, an $18 \mathrm{nmol} / \mathrm{L}(\sim 10 \mathrm{mg} / \mathrm{dL})$ increase in $\mathrm{Lp}(\mathrm{a})$ was associated with an increased risk of CVD and CHD: HR 1.029 (95\% Cl 1.024-1.033) and HR 1.035 (95\% Cl 1.031-1.038), respectively.

For the primary outcome of CVD there was no interaction of LP(a) with age (above or below the median of 57years) $(P=0.16)$, sex $(P=0.27)$, ethnicity $(P>0.23$ for each ethnic group compared to white), baseline CVD $(P=0.24)$, baseline diabetes $(P=0.17)$, statin use $(P=0.61)$, total cholesterol (above or below $8.0 \mathrm{mmol} / \mathrm{L}$ cut-off) $(P=0.38)$, or LDL cholesterol (above or below $2.5 \mathrm{mmol} / \mathrm{L}$ cut-off) $(P=0.72)$. However, there was a borderline interaction of log LP(a) with LDL cholesterol using a cut-off of $3.5 \mathrm{mmol} / \mathrm{L}$ ( $P$ for interaction 0.055). In this model each standard deviation increase in log $L p(a)$ had an $\mathrm{HR}$ of 1.11 (95\% Cl 1.08-1.13) in the group with LDL cholesterol 

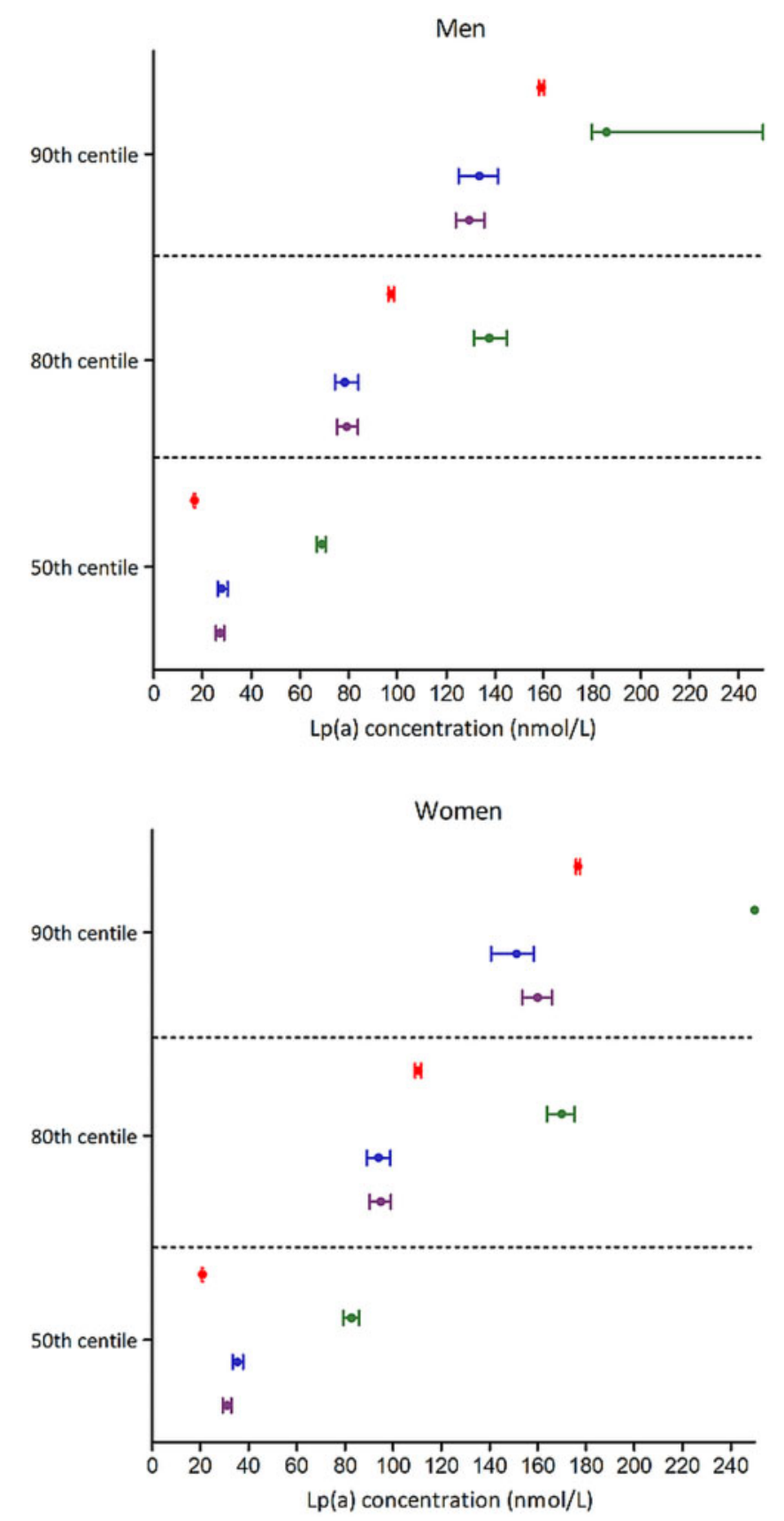

Figure I Centiles of lipoprotein (a), along with $95 \%$ confidence intervals, by sex and ethnicity in the whole cohort. Red denotes white ethnicity, green denotes black ethnicity, blue denotes South Asian, and purple denotes other or mixed ethnicity. Lp(a), lipoprotein (a); nmol/L, nanomoles per litre.

$<3.5 \mathrm{mmol} / \mathrm{L}$ and an HR of 1.15 (95\% Cl 1.12-1.18) in the group with $\mathrm{LDL}$ cholesterol $\geq 3.5 \mathrm{mmol} / \mathrm{L}$.

Data were split into the primary prevention cohort and the highrisk cohort to further explore associations with outcomes. Among the primary prevention group not taking a statin, after adjusting for classical risk factors, the shape of the association of $\mathrm{Lp}(\mathrm{a})$ with composite CVD, fatal CVD, CHD, and aortic valve stenosis was positive and broadly linear (Figure 2). There was also a positive association with PVD, but no evidence of an association with stroke, or heart failure (Figure 2).

Using continuous and multiple different categorical models of $\mathrm{Lp}(\mathrm{a})$ there was a positive association with composite primary CVD outcome (Table 2). Lp(a) as a continuous and categorical variable was also associated with fatal CVD, CHD, PVD, and aortic valve stenosis as well as demonstrating a borderline association with ischaemic stroke after adjusting for classical risk factors, in both the 
Table I Association of categories of lipoprotein (a) with classical risk factors for cardiovascular disease at baseline $(n=413724)$

\begin{tabular}{|c|c|c|c|c|}
\hline & $\operatorname{Lp}(a)$ & $\operatorname{Lp}(a)$ & Lp(a) & $P$-value \\
\hline & $\begin{array}{l}<20 \mathrm{nmol} / \mathrm{L} \\
n=207908\end{array}$ & $\begin{array}{l}20-99.9 \mathrm{nmol} / \mathrm{L} \\
n=119894\end{array}$ & $\begin{array}{l}\geq 100 \mathrm{nmol} / \mathrm{L} \\
n=85932\end{array}$ & \\
\hline Age (years) & $56.3 \pm 8.2$ & $56.7 \pm 8.1$ & $56.9 \pm 8.0$ & $<0.001$ \\
\hline Male sex (\%) & $101214(48.7 \%)$ & $52542(43.8 \%)$ & 37403 (43.5\%) & $<0.001$ \\
\hline \multicolumn{5}{|l|}{ Ethnicity (\%) } \\
\hline White & $201070(96.7 \%)$ & $109952(91.7 \%)$ & 80955 (94.2\%) & $<0.001$ \\
\hline Black & $717(0.3 \%)$ & $3327(2.8 \%)$ & 2404 (2.8\%) & \\
\hline South Asian & $2427(1.2 \%)$ & $2931(2.4 \%)$ & $1064(1.2 \%)$ & \\
\hline Other & $3694(1.8 \%)$ & $3684(3.1 \%)$ & 1509 (1.8\%) & \\
\hline $\begin{array}{l}\text { Systolic blood pressure } \\
\qquad(\mathrm{mmHg})\end{array}$ & $137.9 \pm 18.6$ & $137.7 \pm 18.7$ & $138.4 \pm 18.7$ & $<0.001$ \\
\hline $\begin{array}{l}\text { Diastolic blood pressure } \\
\qquad(\mathrm{mmHg})\end{array}$ & $82.3 \pm 10.2$ & $82.2 \pm 10.1$ & $82.4 \pm 10.1$ & 0.008 \\
\hline Ever smoker $(\%)$ & 22089 (10.6\%) & $12761(10.6 \%)$ & 8995 (10.5\%) & 0.38 \\
\hline Total cholesterol (mmol/L) & $5.59(1.12)$ & $5.75(1.15)$ & $5.86(1.18)$ & $<0.001$ \\
\hline HDL cholesterol (mmol/L) & $1.44(0.39)$ & $1.45(0.38)$ & $1.48(0.38)$ & $<0.001$ \\
\hline Baseline diabetes (\%) & $11463(5.5 \%)$ & $5764(4.8 \%)$ & $4453(5.2 \%)$ & $<0.001$ \\
\hline Baseline CVD (\%) & $11133(5.4 \%)$ & $6900(5.8 \%)$ & $6614(7.7 \%)$ & $<0.001$ \\
\hline Statin use (\%) & $31230(15.0 \%)$ & $18620(15.5 \%)$ & $17376(20.2 \%)$ & $<0.001$ \\
\hline BP medication (\%) & $42159(20.3 \%)$ & $24578(20.5 \%)$ & $19571(22.8 \%)$ & $<0.001$ \\
\hline
\end{tabular}

BP, blood pressure; CVD, cardiovascular disease; HDL, high-density lipoproteins; mmHg, millimetres of mercury; mmol/L, millimoles per litre; nmol/L, nanomoles per litre.

primary prevention cohort and the high-risk cohort (Supplementary material online, Table S2). The association with heart failure was weak. In terms of strength of the point estimates, the association of $\mathrm{Lp}$ (a) with aortic valve stenosis was strong and consistent; those with $L p(a) \geq 175 \mathrm{nmol} / \mathrm{L}$ were at $\sim 85 \%$ increased risk of both outcomes in both the primary prevention cohort and the high-risk cohort (Supplementary material online, Table S2).

\section{Lipoprotein (a) and prediction of cardiovascular disease}

Prediction of incident CVD was specifically explored in the primary prevention cohort. In a model of CVD prediction based on pooled cohort equation risk factors, classical risk factors yielded a C-index of 0.7459 ( $95 \% \mathrm{Cl} 0.7402-0.7517)$. Addition of $L p(a)$ as a continuous variable to these risk factors increased the $\mathrm{C}$-index by +0.0017 (95\% Cl 0.0008-0.0026) (Table 3). On addition of Lp(a) to the model, the improvement in the categorical net reclassification index was $+0.0112 \%(95 \% \mathrm{Cl}+0.0039$ to +0.0184$)$ and most of the improvement was due to upward classification of risk among cases (Table 3). Similar improvements in prediction were obtained when $L p(a)$ was added as a categorical variable, with no clear advantage of one model over another (Table 3). There was a more sizeable improvement in reclassification among the intermediate-risk group at $5-7.49 \% 10$-year risk $(n=16292)$; on addition of continuous $\mathrm{LP}(\mathrm{a})$, the overall net reclassification index in this intermediate-risk group was $+0.0721(95 \% \mathrm{Cl}+0.0323$, $+0.1107)$.

\section{Population attributable fraction of lipoprotein (a)}

In the whole cohort, an $\mathrm{Lp}(\mathrm{a})$ above $100 \mathrm{nmol} / \mathrm{L}$ accounted for $5.8 \%(95 \% \mathrm{Cl} 4.9-6.7 \%)$ of the composite CVD outcome (Figure 3). Moving the threshold for 'high' $L p(a)$ to higher cutoffs resulted in somewhat lower, but still substantial, attributable fractions due to reduced prevalence of the higher cut-offs (Figure 3). The overall PAF lowered to $3.0 \%$ (95\% Cl 2.4-3.6\%) for a cut-off of $L p(a)$ above $175 \mathrm{nmol} / \mathrm{L}$. The proportion of CVD attributable due to any $L p(a)>3.8 \mathrm{nmol} / \mathrm{L}$ in the whole cohort was $8.8 \%(95 \% \mathrm{Cl} 7.6-10.0 \%)$; this is the reduction in risk expected if the whole cohort had $L p(a)$ of $3.8 \mathrm{nmol} / \mathrm{L}$ (Supplementary material online, Figure S2).

\section{Expected benefit of lipoprotein (a) reduction}

We then specifically modelled the scenario in the ongoing Phase 3 trial of an Lp(a) lowering agent. First, among all participants regardless of baseline CVD status ( $n=413734$ ), the CVD event rate was 2.80 (95\% Cl 2.74-2.85) per 1000 person-years. Among those with an Lp(a) above $175 \mathrm{nmol} / \mathrm{L}(n=38111)$, reducing $\mathrm{Lp}(\mathrm{a})$ by $\sim 80 \%$ so that participants have $L p(a) 30-40 \mathrm{nmol} / \mathrm{L}$ range, results in an estimated risk reduction of $23.1 \%(95 \% \mathrm{Cl} 14.9-30.5 \%)$. For prevention of $\mathrm{CHD}$, the same $L p(a)$ reduction was estimated to result in a $28.3 \%$ decrease in risk (95\% Cl 22.8-33.4\%). In a sensitivity analysis removing individuals with $\operatorname{Lp}(\mathrm{a})$ above the reported measurable range 

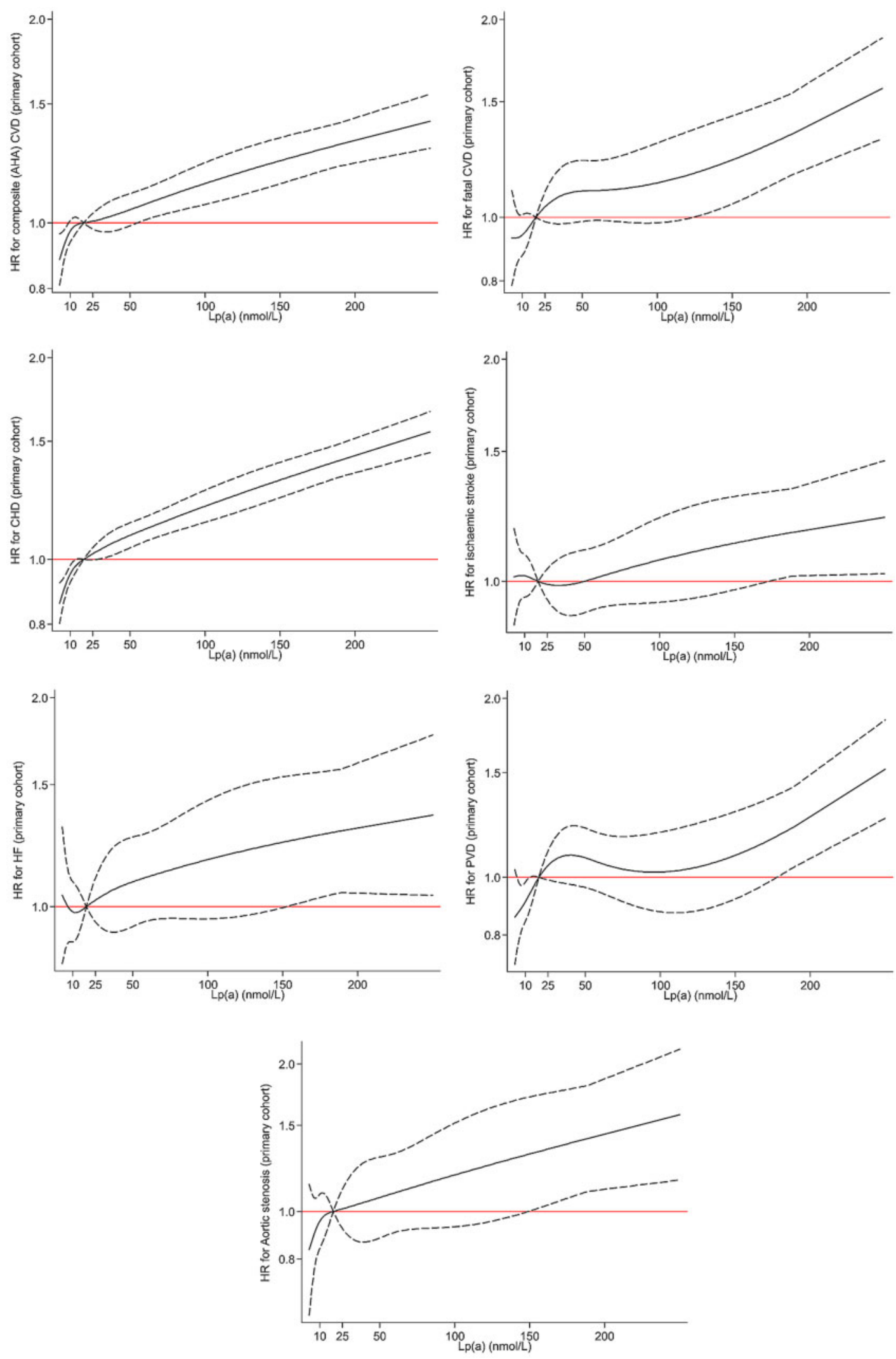

Figure 2 Association of $L p(a)$ with outcomes after adjusting for classical risk factors among participants without baseline cardiovascular disease and not taking a statin. Referent (hazard ratio $=1.0$ ) at $19 \mathrm{nmol} / \mathrm{L}$. AHA, American Heart Association; HF, heart failure; HR, hazard ratio; Lp(a), lipoprotein (a); nmol/L: nanomoles per litre; PVD, peripheral vascular disease. 
Table 2 Association of $\mathrm{Lp}(\mathrm{a})$ (hazard ratio and 95\% $\mathrm{Cl}$ ) as a continuous variable (per $1 \mathrm{SD}$ increase in log $\mathrm{Lp}(\mathrm{a})$ ) and as a categorical variable with the primary composite CVD outcome after adjusting for classical risk factors ${ }^{a}$

\begin{tabular}{|c|c|c|c|c|}
\hline \multirow[t]{2}{*}{ Lp(a) conc. } & \multicolumn{2}{|c|}{ Primary prevention cohort } & \multicolumn{2}{|c|}{ High-risk cohort $^{b}$} \\
\hline & $N$ (n events) & HR (95\% CI) & $N$ (n events) & HR (95\% CI) \\
\hline Per $1 \mathrm{SD}$ & $340339(6125)$ & $1.13(1.10-1.16)$ & $73395(3941)$ & $1.11(1.08-1.14)$ \\
\hline$<20 \mathrm{nmol} / \mathrm{L}$ & $173639(2857)$ & Ref & $34269(1689)$ & Ref \\
\hline $20-99.9 \mathrm{nmol} / \mathrm{L}$ & 99499 (1802) & $1.11(1.05-1.18)$ & $20395(1086)$ & $1.11(1.03-1.20)$ \\
\hline$\geq 100 \mathrm{nmol} / \mathrm{L}$ & $67201(1466)$ & $1.37(1.28-1.46)$ & $18731(1166)$ & $1.30(1.21-1.41)$ \\
\hline$<20 \mathrm{nmol} / \mathrm{L}$ & $173639(2857)$ & Ref & $34269(1689)$ & Ref \\
\hline $20-124.9 \mathrm{nmol} / \mathrm{L}$ & $114093(2086)$ & $1.13(1.06-1.19)$ & $23130(1241)$ & $1.11(1.03-1.20)$ \\
\hline$\geq 125 \mathrm{nmol} / \mathrm{L}$ & 52607 (1182) & $1.40(1.31-1.50)$ & $15996(1011)$ & $1.34(1.24-1.45)$ \\
\hline$<20 \mathrm{nmol} / \mathrm{L}$ & $173639(2857)$ & Ref & $34269(1689)$ & Ref \\
\hline $20-149.9 .9 \mathrm{nmol} / \mathrm{L}$ & $127636(2371)$ & $1.15(1.09-1.21)$ & $26031(1428)$ & $1.13(1.06-1.22)$ \\
\hline$\geq 150 \mathrm{nmol} / \mathrm{L}$ & 39064 (897) & $1.43(1.33-1.55)$ & $13095(824)$ & $1.35(1.24-1.47)$ \\
\hline$<20 \mathrm{nmol} / \mathrm{L}$ & 173639 (2857) & Ref & $34269(1689)$ & Ref \\
\hline $20-174.9 \mathrm{nmol} / \mathrm{L}$ & $138836(2626)$ & $1.17(1.11-1.23)$ & $28879(1608)$ & $1.15(1.08-1.23)$ \\
\hline$\geq 175 \mathrm{nmol} / \mathrm{L}$ & $27864(642)$ & $1.44(1.32-1.58)$ & $10247(644)$ & $1.36(1.24-1.49)$ \\
\hline $\begin{array}{l}\text { Below the sex and ethni- } \\
\text { city-specific } 80 \text { th centile }\end{array}$ & $275892(4672)$ & Ref & $54886(2768)$ & Ref \\
\hline $\begin{array}{l}\text { Above the sex and ethni- } \\
\text { city-specific } 80 \text { th centile }\end{array}$ & $64447(1453)$ & $1.31(1.24-1.39)$ & 18509 (1173) & $1.26(1.18-1.35)$ \\
\hline
\end{tabular}

$\mathrm{Cl}$, confidence interval; CVD, cardiovascular disease; HDL, high-density lipoprotein; HR, hazard ratio; Lp(a), lipoprotein (a); nmol/L, nanomoles per litre; SD, standard deviation. ${ }^{\mathrm{a} A g e,}$ sex, total cholesterol, HDL cholesterol, ethnicity, smoking, systolic blood pressure, blood pressure medications, and baseline diabetes.

bParticipants with baseline CVD or taking a statin; additionally, adjusted for baseline CVD and statin use.

$(>189 \mathrm{nmol} / \mathrm{L})$, reduction of $\mathrm{Lp}(\mathrm{a})$ in the range of $175-189 \mathrm{nmol} / \mathrm{L}$ to $30-40 \mathrm{nmol} / \mathrm{L}$ results in an estimated CVD risk reduction of $16.3 \%$ (95\% Cl 2.5-28.2\%).

Specifically investigating participants with baseline CVD $(n=24647)$ the CVD event rate was 11.7 (95\% Cl 11.3-12.2) per 1000 person years. Among those with an $\mathrm{Lp}(\mathrm{a})$ above $175 \mathrm{nmol} / \mathrm{L}$ $(n=3568)$, similar $L p(a)$ reductions are estimated to reduce CVD risk by $20.0 \%(95 \% \mathrm{Cl} 2.1-34.6 \%)$ and CHD risk by $24.4 \%(95 \% \mathrm{Cl}$ 13.5-33.9\%).

\section{Discussion}

In this large cohort of over 400000 individuals, a high proportion of the UK Biobank cohort had what might conventionally be called high $\mathrm{Lp}(\mathrm{a})$ levels; $20.8 \%$ above $100 \mathrm{nmo} / \mathrm{L}$ and $9.2 \%$ above $175 \mathrm{nmol} / \mathrm{L}$. Intraindividual concordance in $L p(a)$ levels across visits years apart was high. We noted a broadly linear relationship of $L p(a)$ with composite fatal or nonfatal CVD, fatal CVD, and fatal or non-fatal CHD, PVD, and aortic stenosis with associations largely unaffected by other risk factors. Therefore, population attributable fractions for $L p(a)$ were sizable. Further, we estimate that targeting $L p(a)$ lowering therapy in ongoing trials to those with $L p(a)$ concentrations above $175 \mathrm{nmol} / \mathrm{L}$ would reduce CVD incidence by around 20\% (regardless of baseline CVD status). This extends estimates ${ }^{22}$ from smaller studies to a current ongoing trial. Collectively, our results seem to justify the recent ESC/ EAS guidelines ${ }^{13}$ suggesting consideration for at least a one-time $L p(a)$ measurement in all people being screened for CVD risk.
Genetic data suggest large reductions in $L p(a)$ are required to show clinical benefit, although there is some disagreement as to the extent of the reduction required. ${ }^{4,5}$ The study of Burgess et al. ${ }^{4}$ estimated that a $10 \mathrm{mg} / \mathrm{dL}$ decrease in $\mathrm{Lp}(\mathrm{a})(\sim 18 \mathrm{nmol} / \mathrm{L})$ would cause a $5.8 \%$ decrease in odds of $\mathrm{CHD}$, whereas Lamina and Kronenberg ${ }^{5}$ estimated it would be an $8.8 \%$ reduction in odds. Our estimate that an $18 \mathrm{nmol} / \mathrm{L}$ increase in $\mathrm{Lp}(\mathrm{a})$ would be associated with a $3.5 \%$ increased CHD risk is therefore somewhat more conservative than the genetic data. Mendelian randomization studies may offer better causal insights than observational studies for many traits, although pleiotropy and lifelong exposure to elevated levels of $L p(a)$ may also have an impact on estimates. ${ }^{23}$ Our more conservative estimate, if correct, would imply a requirement for greater $L p(a)$ reduction to achieve reduced CVD risk. Despite this, recent Phase 2 trial data show that the drug AKCEA-APO(a)-LRx (also called TQJ230) reduces $L p(a)$ substantially, with $80-90 \%$ reductions in patients with established CVD and high Lp(a) levels, depending on dosing. ${ }^{21,24}$ This antisense oligonucleotide inhibits the production of apolipoprotein(a), thereby reducing $L p(a)$. Phase 3 outcome trials are underway ${ }^{7}$ and specifically target those with elevated $L p(a)$. Furthermore, there is also emerging evidence that proprotein convertase subtilisin/kexin type 9 inhibitors lower LP(a) independent of LDL cholesterol reduction, and this reduction contributes to CVD event reduction ${ }^{9}$ and lowering of PVD risk. ${ }^{25,26}$ These findings provide a currently licensed drug to help lower Lp(a) by a modest amount.

Our data suggest that a drug that prevents CVD through Lp(a) lowering may also have benefits for individual components of the CVD composite, and for PVD outcomes, as well as aortic stenosis. 
Table 3 Improvement in prediction of cardiovascular disease among participants in the primary prevention cohort measured by the C-statistic and categorical net reclassification index (across 10-year risk boundaries of $<5 \%, 5-7.49 \%$, $\geq 7.5 \%$ )

\begin{tabular}{|c|c|c|c|c|c|}
\hline Model & $\begin{array}{l}\text { C-index } \\
(95 \% \mathrm{Cl})\end{array}$ & $\begin{array}{c}\text { Change in C-index } \\
(95 \% \mathrm{Cl})\end{array}$ & $\begin{array}{c}\text { Overall NRI } \\
(95 \% \mathrm{CI})\end{array}$ & $\begin{array}{l}\text { Case NRI } \\
(95 \% \mathrm{Cl})\end{array}$ & $\begin{array}{l}\text { Control NRI } \\
(95 \% \mathrm{CI})\end{array}$ \\
\hline Classical risk factors $^{\mathrm{a}}$ & $\begin{array}{c}0.7459 \\
(0.7402-0.7517)\end{array}$ & & & & \\
\hline $\begin{array}{l}\text { Classical risk factors }+ \text { continuous log } \\
\text { Lp(a) }\end{array}$ & & $\begin{array}{c}+0.0017 \\
(0.0008-0.0026)\end{array}$ & $\begin{array}{c}+0.0112 \\
(+0.0039,+0.0184)\end{array}$ & $\begin{array}{c}0.0118 \\
(+0.0046,+0.0190)\end{array}$ & $\begin{array}{c}-0.0007 \\
(-0.0012,-0.0002)\end{array}$ \\
\hline $\begin{array}{l}\text { Classical risk factors + categorical } \\
\text { Lp(a) at }<20,20-99.9 \text {, and } \\
>100 \mathrm{nmol} / \mathrm{L}\end{array}$ & & $\begin{array}{c}+0.0018 \\
(0.0009-0.0026)\end{array}$ & $\begin{array}{c}+0.0108 \\
(+0.0040,+0.0175)\end{array}$ & $\begin{array}{c}0.0118 \\
(+0.0050,+0.0184)\end{array}$ & $\begin{array}{c}-0.0009 \\
(-0.0014,-0.0004)\end{array}$ \\
\hline $\begin{array}{l}\text { Classical risk factors }+ \text { categorical } \\
L p(a) \text { at }<20,20-149.9 \text {, and } \\
>150 \mathrm{nmol} / \mathrm{L}\end{array}$ & & $\begin{array}{c}+0.0016 \\
(0.0007-0.0024)\end{array}$ & $\begin{array}{c}+0.0135 \\
(+0.0063,+0.0203)\end{array}$ & $\begin{array}{c}0.0144 \\
(+0.0063,+0.0203)\end{array}$ & $\begin{array}{c}-0.0009 \\
(-0.0014,-0.0004)\end{array}$ \\
\hline $\begin{array}{l}\text { Classical risk factors }+ \text { binary } \operatorname{Lp}(a) \text { at } \\
\text { sex and ethnicity-specific 80th } \\
\text { percentile }\end{array}$ & & $\begin{array}{c}+0.0015 \\
(0.0007-0.0023)\end{array}$ & $\begin{array}{c}+0.0111 \\
(+0.0045,+0.0180)\end{array}$ & $\begin{array}{c}0.0115 \\
(+0.0050,+0.0184)\end{array}$ & $\begin{array}{c}-0.0004 \\
(-0.0009,-0.0001)\end{array}$ \\
\hline
\end{tabular}

CVD, cardiovascular disease; HDL, high-density lipoprotein; Lp(a), lipoprotein (a); nmol/L, nanomoles per litre; NRI, net reclassification index. ${ }^{a}$ Age, sex, total cholesterol, HDL cholesterol, ethnicity, smoking, systolic blood pressure, blood pressure medications, and baseline diabetes.

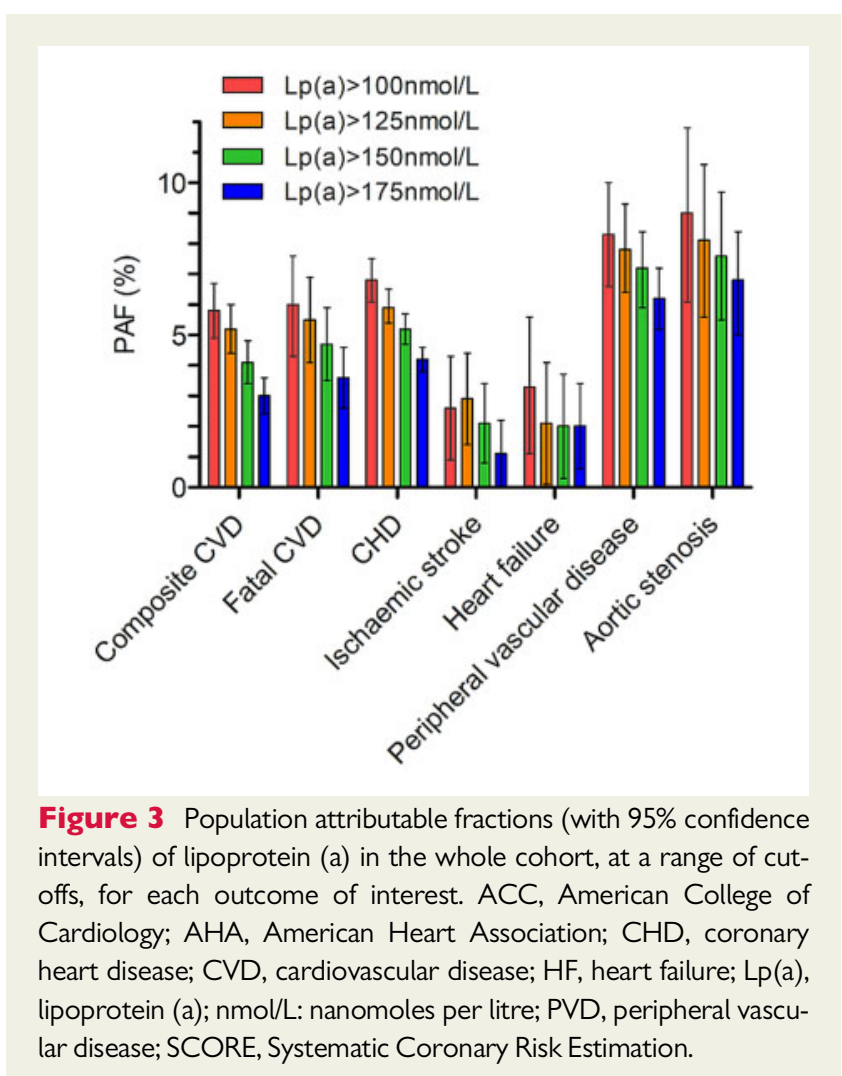

Our models suggest potential benefit in both primary and secondary prevention. Although $\mathrm{Lp}(\mathrm{a})$ only adds moderate information to risk discrimination metrics and is more expensive than traditional lipid measurements, ${ }^{27}$ the fact that the marker is (i) causal, (ii) largely orthogonal to other risk factors, (iii) stable across life course, (iv) has a substantial population attributable fraction, and ( $v$ ) may help guide therapy allocation, enhances arguments that measurement of $L p(a)$ should become more common in the evaluation of CVD risk. Notably, the reported improvement in C-statistics with Lp(a) was around four times higher than previously reported for C-reactive protein. ${ }^{28}$ In particular, we show that incorporation of $L p(a)$ into risk scores targeted at intermediate-risk groups would lead to changes in a greater proportion of treatment decisions than measurement in the whole general population. This may be a method to tie-break treatment decisions in a targeted manner, in line with current US guidelines. There are a range of suggested cut-offs for LP(a) in clinical practice. $^{10,15,29}$ The data reported here are consistent with the approach of the $L p(a) H O R I Z O N$ trial in identifying $>175 \mathrm{nmol} / \mathrm{L}$ as a risk marker. The results of this and other trials should help inform on the most cost-effective cut-offs used in future for clinical care.

The ethnicity-specific centiles we report confirm and extend observations in other cohorts, most noticeably higher $L p(a)$ in black people. ${ }^{30}$ We would expect a higher PAF for CVD outcomes in black ethnicities due to higher prevalence of the exposure, but low numbers of black participants restrict our ability to formally test this hypothesis in this cohort. Overall, we note no strong interaction of $L p(a)$ with demographics or other risk factors suggesting that $L p(a)$ is similarly associated with risk in different subgroups. Previous work in primary prevention cohorts from EPIC-Norfolk and the Copenhagen City Heart Study $(n=16654)$ has suggested that the association between elevated Lp(a) (>80th percentile) and CVD events is attenuated at LDL cholesterol levels below $2.5 \mathrm{mmol} / \mathrm{L}^{31}$ Likewise, data from the Women's Health Study and JUPITER trials reported stronger associations of $\mathrm{LP}(\mathrm{a})$ above $50 \mathrm{mg} / \mathrm{dL}$ with CVD risk at total cholesterol levels above $5.7 \mathrm{mmol} / \mathrm{L}^{3}$ We report borderline evidence that continuous $L p(a)$ may have a slightly weaker risk association in people with directly measured LDL cholesterol $<3.5 \mathrm{mmol} / \mathrm{L}$, but this is not evident at a cut-off of $2.5 \mathrm{mmol} / \mathrm{L}$, and the association with 
CVD remains clinically relevant and statistically significant in both LDL cholesterol groups.

The PAFs we report for $L p(a)$ may usefully be put in context of estimates of PAFs for other risk factors. The ARIC study reported PAFs at examination four (among white participants) of $21 \%$ for hypertension, $13 \%$ for diabetes, $10 \%$ for hypercholesterolaemia, and $12 \%$ for smoking. ${ }^{32}$ Similarly, in the Emerging Risk Factors Collaboration, the PAF for diabetes in vascular death has been estimated at $11 \%$ (assuming a $10 \%$ diabetes prevalence). ${ }^{33}$ In terms of CVD risk prediction, our data are also broadly in line with the Emerging Risk Factors Collaboration (ERFC), where data from 165544 participants in 37 prospective studies showed Lp(a) improved the C-index by +0.0016 (95\% Cl 0.0009-0.0023), ${ }^{34}$ lending strong external validity to these new reported findings. It is also in agreement with data from other large cohort studies. ${ }^{35-38}$ Our data extend these findings in a large cohort with substantial power, using a single methodologically strong $L p(a)$ measurement, where we also estimated the PAF for a range of CVD outcomes independently due to $L p(a)$ elevation.

The strengths of our study include the large cohort size at an age-relevant to CVD risk scoring and biochemistry assays performed in a single dedicated central laboratory. We were also able to extensively adjust our models for classical risk factors and separately analysed participants already on statins as well as those with previous CVD. We were also able to investigate at other cardiovascular outcomes. Potential limitations include the relatively low average CVD risk of participants, although risk prediction models performed broadly in line with expectations. UK Biobank is not representative of the whole UK population, ${ }^{35}$ and while this is generally not a concern in investigating risk associations ${ }^{39}$ it will have an impact on calculated population attributable fractions. The population attributable fractions we observe here cannot be taken as representative of the UK population as a whole. However, due to the under-representation of black people in UK Biobank, it may be that our estimates are conservative. In addition, the 80th centile we report here of $105 \mathrm{nmol} / \mathrm{L}$ corresponds broadly to previously reported 80th centiles in 3000 men and 3000 women from the Copenhagen General Population Study $(50 \mathrm{mg} / \mathrm{dL}) .{ }^{11}$ The upper reported $\mathrm{Lp}(\mathrm{a})$ concentration in UK Biobank is $189 \mathrm{nmol} / \mathrm{L}$, limiting our ability to investigate associations higher than this concentration. Finally, UK biobank is a primarily primary prevention low-risk population, and extrapolation to secondary prevention settings and modelled therapeutic benefits (such as the LP(a)HORIZON trial) must be interpreted with caution. However, the secondary prevention group is still sizeable and has appreciably higher CVD events rates than the cohort as a whole, and we observe no evidence of interaction of the PAF for $L p(a)$ lowering by baseline CVD status. Our estimates of expected therapy effects among the exposed ( $L p(a)$ above $175 \mathrm{nmol} / \mathrm{L})$ should be robust to differences in representativeness, since we only consider those with high $\operatorname{Lp}(\mathrm{a})$ as exposed.

In conclusion, in this, the largest single prospective study of $\operatorname{Lp}(\mathrm{a})$ levels, our findings add strong support for recent guideline recommended one-time measurement of $L p(a)$ in cardiovascular risk assessment to identify a large proportion with markedly elevated levels sufficient to contribute to atherothrombotic risk. Our work also provides support to the ongoing programmes to develop efficacious Lp(a) lowering drugs.

\section{Supplementary material}

Supplementary material is available at European Journal of Preventive Cardiology online.

\section{Acknowledgements}

This research was conducted using the UK Biobank resource. We thank the participants of the UK Biobank. The work was performed under UK biobank project number 9310. We thank Liz Coyle (University of Glasgow) for assistance with manuscript preparation.

\section{Funding}

This work was supported by a grant from Chest, Heart \& Stroke Scotland [Res16/A165], and by the British Heart Foundation Research Excellence Award [RE/18/6/34217].

Conflict of interest: P.Welsh. reports grant income from Roche Diagnostics. P.B.M. reports speaker honoraria from AstraZeneca and Novartis. J.A.dL. reports consulting income from Amgen for participation in steering committee, Regneron for participation on Data Safety Monitoring Board, and grant support from Roche Diagnostics, and Abbott Diagnostics. P.Willeit. reports personal fees from Novartis Pharmaceuticals. N.S. has consulted for Amgen and Sanofi. All conflicts are outside the submitted work. All other authors have no conflict of interest to declare.

\section{References}

1. Willeit P, Ridker PM, Nestel PJ, Simes J, Tonkin AM, Pedersen TR, Schwartz GG, Olsson AG, Colhoun HM, Kronenberg F, Drechsler C, Wanner C, Mora S, Lesogor A, Tsimikas S. Baseline and on-statin treatment lipoprotein(a) levels for prediction of cardiovascular events: individual patient-data meta-analysis of statin outcome trials. Lancet 2018;392:1311-1320.

2. Waldeyer C, Makarova N, Zeller T, Schnabel RB, Brunner FJ, Jørgensen T, Linneberg A, Niiranen T, Salomaa V, Jousilahti P, Yarnell J, Ferrario MM, Veronesi G, Brambilla P, Signorini SG, lacoviello L, Costanzo S, Giampaoli S, Palmieri L, Meisinger C, Thorand B, Kee F, Koenig W, Ojeda F, Kontto J, Landmesser U, Kuulasmaa K, Blankenberg S. Lipoprotein(a) and the risk of cardiovascular disease in the European population: results from the BiomarCaRE consortium. Eur Heart J 2017;38:2490-2498.

3. Cook NR, Mora S, Ridker PM. Lipoprotein(a) and cardiovascular risk prediction among women. J Am Coll Cardiol 2018;72:287-296.

4. Burgess S, Ference BA, Staley JR, Freitag DF, Mason AM, Nielsen SF, Willeit $P$, Young R, Surendran P, Karthikeyan S, Bolton TR, Peters JE, Kamstrup PR, Tybjærg-Hansen A, Benn M, Langsted A, Schnohr P, Vedel-Krogh S, Kobylecki C), Ford I, Packard C, Trompet S, Jukema JW, Sattar N, Di Angelantonio E, Saleheen D, Howson JMM, Nordestgaard BG, Butterworth AS, Danesh J; for the European Prospective Investigation Into Cancer and Nutrition-Cardiovascular Disease (EPIC-CVD) Consortium. Association of LPA variants with risk of coronary disease and the implications for lipoprotein(a)-lowering therapies. JAMA Cardiol 2018;3:619.

5. Lamina C, Kronenberg F; for the Lp(a)-GWAS-Consortium. Estimation of the required lipoprotein(a)-lowering therapeutic effect size for reduction in coronary heart disease outcomes: a Mendelian randomization analysis. JAMA Cardiol 2019; 4:575-579.

6. Tsimikas S, Fazio S, Ferdinand KC, Ginsberg HN, Koschinsky ML, Marcovina SM, Moriarty PM, Rader DJ, Remaley AT, Reyes-Soffer G, Santos RD, Thanassoulis G, Witztum JL, Danthi S, Olive M, Liu L. NHLBI Working Group 
Recommendations to reduce lipoprotein(a)-mediated risk of cardiovascular disease and aortic stenosis. J Am Coll Cardiol 2018;71:177-192.

7. Assessing the Impact of Lipoprotein (a) Lowering With TQJ230 on Major Cardiovascular Events in Patients With CVD (LP(a)HORIZON). https://clinical trials.gov/ct2/show/NCT04023552.

8. O'Donoghue ML, Fazio S, Giugliano RP, Stroes ESG, Kanevsky E, Gouni-Berthold I, Im KAh, Lira Pineda A, Wasserman SM, Češka R, Ezhov MV, Jukema JW, Jensen HK, Tokgözoğlu SL, Mach F, Huber K, Sever PS, Keech AC, Pedersen TR, Sabatine MS. Lipoprotein(a), PCSK9 inhibition, and cardiovascular risk. Circulation 2019;139:1483-1492.

9. Bittner VA, Szarek M, Aylward PE, Bhatt DL, Diaz R, Edelberg JM, Fras Z, Goodman SG, Halvorsen S, Hanotin C, Harrington RA, Jukema JW, Loizeau V, Moriarty PM, Moryusef A, Pordy R, Roe MT, Sinnaeve P, Tsimikas S, Vogel R, White HD, Zahger D, Zeiher AM, Steg PG, Schwartz GG. Effect of alirocumab on lipoprotein(a) and cardiovascular risk after acute coronary syndrome. J Am Coll Cardiol 2020;75:133-144.

10. Wilson DP, Jacobson TA, Jones PH, Koschinsky ML, McNeal CJ, Nordestgaard BG, Orringer CE. Use of lipoprotein(a) in clinical practice: a biomarker whose time has come. A scientific statement from the National Lipid Association. J Clin Lipidol 2019;13:374-392.

11. Nordestgaard BG, Chapman MJ, Ray K, Borén J, Andreotti F, Watts GF, Ginsberg H, Amarenco P, Catapano A, Descamps OS, Fisher E, Kovanen PT, Kuivenhoven JA, Lesnik P, Masana L, Reiner Z, Taskinen M-R, Tokgözoglu L, Tybjærg-Hansen A. Lipoprotein(a) as a cardiovascular risk factor: current status. Eur Heart J 2010;31:2844-2853.

12. ESC Committee for Practice Guidelines (CPG) 2008-2010 and 2010-2012 Committees. ESC/EAS guidelines for the management of dyslipidaemias: the task force for the management of dyslipidaemias of the European Society of Cardiology (ESC) and the European Atherosclerosis Society (EAS). Eur Heart J 2011;32:1769-1818.

13. Mach F, Baigent C, Catapano AL, Koskinas KC, Casula M, Badimon L, Chapman MJ, De Backer GG, Delgado V, Ference BA, Graham IM, Halliday A, Landmesser U, Mihaylova B, Pedersen TR, Riccardi G, Richter DJ, Sabatine MS, Taskinen M-R, Tokgozoglu L, Wiklund O; ESC Scientific Document Group. 2019 ESC/EAS Guidelines for the management of dyslipidaemias: lipid modification to reduce cardiovascular risk. Eur Heart J 2020;41:111-188.

14. Ellis KL, Pérez de Isla L, Alonso R, Fuentes F, Watts GF, Mata P. Value of measuring lipoprotein(a) during cascade testing for familial hypercholesterolemia. J Am Coll Cardiol 2019;73:1029-1039.

15. Grundy SM, Stone NJ, Bailey AL, Beam C, Birtcher KK, Blumenthal RS, Braun LT, de Ferranti S, Faiella-Tommasino J, Forman DE, Goldberg R, Heidenreich PA, Hlatky MA, Jones DW, Lloyd-Jones D, Lopez-Pajares N, Ndumele CE, Orringer CE, Peralta CA, Saseen JJ, Smith SC Jr, Sperling L, Virani SS, Yeboah J. 2018 AHA/ACC/AACVPR/AAPA/ABC/ACPM/ADA/AGS/APhA/ASPC/NLA/PCNA

Guideline on the management of blood cholesterol: a report of the American College of Cardiology/American Heart Association Task Force on Clinical Practice Guidelines. Circulation 2019;139:e1082-e1143.

16. Kamstrup PR, Tybjærg-Hansen A, Steffensen R, et al. Genetically elevated lipoprotein(a) and increased risk of myocardial infarction. JAMA 2009;301: 2331-2339

17. Anderson TJ, Grégoire J, Pearson G], Barry AR, Couture P, Dawes M, Francis GA, Genest J, Grover S, Gupta M, Hegele RA, Lau DC, Leiter LA, Lonn E, Mancini GBJ, McPherson R, Ngui D, Poirier P, Sievenpiper JL, Stone JA, Thanassoulis G, Ward R. 2016 Canadian Cardiovascular Society guidelines for the management of dyslipidemia for the prevention of cardiovascular disease in the adult. Can J Cardiol 2016;32:1263-1282.

18. Collins R. What makes UK Biobank special? Lancet 2012;379:1173-1174.

19. Sudlow C, Gallacher J, Allen N, Beral V, Burton P, Danesh J, Downey P, Elliott P, Green J, Landray M, Liu B, Matthews P, Ong G, Pell J, Silman A, Young A, Sprosen T, Peakman T, Collins R. UK Biobank: an open access resource for identifying the causes of a wide range of complex diseases of middle and old age. PLoS Med 2015;12:e1001779.

20. Elliott P, Peakman TC; on behalf of UK Biobank. The UK Biobank sample handling and storage protocol for the collection, processing and archiving of human blood and urine. Int J Epidemiol 2008;37:234-244.

21. Viney NJ, van Capelleveen JC, Geary RS, Xia S, Tami JA, Yu RZ, Marcovina SM, Hughes SG, Graham MJ, Crooke RM, Crooke ST, Witztum JL, Stroes ES,
Tsimikas S. Antisense oligonucleotides targeting apolipoprotein(a) in people with raised lipoprotein(a): two randomised, double-blind, placebo-controlled, doseranging trials. Lancet 2016;388:2239-2253.

22. Madsen CM, Kamstrup PR, Langsted A, Varbo A, Nordestgaard BG. Lipoprotein(a)-lowering by $50 \mathrm{mg} / \mathrm{dL}(105 \mathrm{nmol} / \mathrm{L})$ may be needed to reduce cardiovascular disease $20 \%$ in secondary prevention: a population-based study. Arterioscler Thromb Vasc Biol 2020;40:255-266.

23. Würtz $P$, Kangas AJ, Soininen $P$, Lehtimäki T, Kähönen M, Viikari JS, Raitakari OT, Järvelin M-R, Davey Smith G, Ala-Korpela M. Lipoprotein subclass profiling reveals pleiotropy in the genetic variants of lipid risk factors for coronary heart disease: a note on mendelian randomization studies. J Am Coll Cardiol 2013;62: 1906-1908.

24. Langsted A, Nordestgaard BG. Antisense oligonucleotides targeting lipoprotein(a). Curr Atheroscler Rep 2019;21:30.

25. Schwartz GG, Steg PG, Szarek M, Bittner VA, Diaz R, Goodman SG, Kim Y-U, Jukema JW, Pordy R, Roe MT, White HD, Bhatt DL; ODYSSEY OUTCOMES Committees and Investigators. Peripheral artery disease and venous thromboembolic events after acute coronary syndrome: role of lipoprotein(a) and modification by alirocumab: prespecified analysis of the ODYSSEY OUTCOMES randomized clinical trial. Circulation 2020;141:1608-1617.

26. Marston NA, Gurmu Y, Melloni GEM, Bonaca M, Gencer B, Sever PS, Pedersen TR, Keech AC, Roselli C, Lubitz SA, Ellinor PT, O'Donoghue ML, Giugliano RP Ruff CT, Sabatine MS. The Effect of PCSK9 (Proprotein Convertase Subtilisin/ Kexin Type 9) inhibition on the risk of venous thromboembolism. Circulation 2020;141:1600-1607.

27. Tsimikas S. A test in context: lipoprotein(a): diagnosis, prognosis, controversies, and emerging therapies. J Am Coll Cardiol 2017;69:692-711.

28. Emerging Risk Factors Collaboration. C-reactive protein, fibrinogen, and cardiovascular disease prediction. N Engl J Med 2012;367:1310-1320.

29. Cegla J, Neely RDG, France M, Ferns G, Byrne CD, Halcox J, Datta D, Capps N, Shoulders C, Qureshi N, Rees A, Main L, Cramb R, Viljoen A, Payne J, Soran H. HEART UK consensus statement on Lipoprotein(a): a call to action. Atherosclerosis 2019;291:62-70.

30. Marcovina SM, Albers JJ. Lipoprotein (a) measurements for clinical application. J Lipid Res 2016;57:526-537.

31. Verbeek R, Hoogeveen RM, Langsted A, Stiekema LCA, Verweij SL, Hovingh GK, Wareham NJ, Khaw K-T, Boekholdt SM, Nordestgaard BG, Stroes ESG. Cardiovascular disease risk associated with elevated lipoprotein(a) attenuates at low low-density lipoprotein cholesterol levels in a primary prevention setting. Eur Heart J 2018;39:2589-2596.

32. Cheng S, Claggett B, Correia AW, Shah AM, Gupta DK, Skali H, Ni H, Rosamond WD, Heiss G, Folsom AR, Coresh J, Solomon SD. Temporal trends in the population attributable risk for cardiovascular disease: the Atherosclerosis Risk in Communities Study. Circulation 2014;130:820-828.

33. Sarwar N, Gao P, Seshasai SRK, Gobin R, Kaptoge S, Di Angelantonio E, Ingelsson E, Lawlor DA, Selvin E, Stampfer M, Stehouwer CDA, Lewington S, Pennells L, Thompson A, Sattar N, White IR, Ray KK, Danesh J; Emerging Risk Factors Collaboration. Diabetes mellitus, fasting blood glucose concentration, and risk of vascular disease: a collaborative meta-analysis of 102 prospective studies. Lancet 2010;375:2215-2222.

34. Di Angelantonio E, Gao P, Danesh J; Emerging Risk Factors Collaboration. Lipidrelated markers and cardiovascular disease prediction. JAMA 2012;308:1969-2506.

35. Fry A, Littlejohns T], Sudlow C, Doherty N, Adamska L, Sprosen T, Collins R, Allen NE. Comparison of sociodemographic and health-related characteristics of UK biobank participants with those of the general population. Am J Epidemiol 2017;186:1026-1034.

36. Kamstrup PR, Tybjærg-Hansen A, Nordestgaard BG. Extreme lipoprotein(a) levels and improved cardiovascular risk prediction. J Am Coll Cardiol 2013;61:1146-1156.

37. Willeit P, Kiechl S, Kronenberg F, Witztum JL, Santer P, Mayr M, Xu Q, Mayr A, Willeit J, Tsimikas S. Discrimination and net reclassification of cardiovascular risk with lipoprotein(a). J Am Coll Cardiol 2014;64:851-860.

38. Verbeek R, Sandhu MS, Hovingh GK, Sjouke B, Wareham NJ, Zwinderman AH, Kastelein JJP, Khaw K-T, Tsimikas S, Boekholdt SM. Lipoprotein(a) improves cardiovascular risk prediction based on established risk algorithms. J Am Coll Cardiol 2017;69:1513-1515.

39. Keyes KM, Westreich D. UK Biobank, big data, and the consequences of nonrepresentativeness. Lancet 2019;393:1297. 